\title{
The economic evaluation of the benefits and costs of carbon capture and storage
}

\author{
Anthony Heyes* and Bogdan Urban \\ Department of Economics, \\ University of Ottawa, \\ 120 University Private, Social Sciences, \\ Building, Ottawa, Ontario, K1N 6N5, Canada \\ Email: aheyes@uottawa.ca \\ Email: iurban@uottawa.ca \\ *Corresponding author
}

\begin{abstract}
Carbon capture and storage has received a lot of attention in recent years due to its attractiveness as a potential solution for climate stabilisation. Since it is based on a suite of mature, well known technologies, most of the cost reductions have already occurred. Recently adopted social cost of carbon figures to advise policies in the USA and Canada currently point towards lower benefits than costs from carbon capture and storage, but not always by a wide margin. It is difficult to make a case for large-scale deployment under these conditions, but they are subject to change as strands of the economic literature support significantly higher social cost of carbon estimates and upcoming commercial applications of carbon capture and storage to power generation may prove economically viable.
\end{abstract}

Keywords: social cost; benefit; cost; carbon; capture; storage; abatement; global; warming; greenhouse.

Reference to this paper should be made as follows: Heyes, A. and Urban, B. (2019) 'The economic evaluation of the benefits and costs of carbon capture and storage', Int. J. Risk Assessment and Management, Vol. 22, Nos. 3/4, pp.324-341.

Biographical notes: Anthony Heyes is a Professor of Economics and Tier 1 Canada Research Chair in Environmental Economics at University of Ottawa and a part-time Professor in the School of Business at the University of Sussex. $\mathrm{He}$ has degrees from Cambridge and McGill Universities and has researched and published extensively on issues at the interface between energy, environment and regulation.

Bogdan Urban is a $\mathrm{PhD}$ candidate at University of Ottawa. He has degrees from McMaster University and specialises in environmental economics.

\section{Introduction}

In their Fifth Assessment Report the Intergovernmental Panel on Climate Change (IPCC) concluded that global greenhouse-gas emissions grew at $2.2 \%$ per year between 2000 and 2010 and are likely to increase by approximately $10 \%$ by 2030 . At that point there would 
be an estimated $33 \%-66 \%$ chance of not going over the $2^{\circ} \mathrm{C}$ rise in global mean surface temperature relative to pre-industrial times, which is considered manageable by the scientific community (IPCC, 2014) and the upper target of the Paris Agreement (UNFCCC, 2015). The IPCC relies heavily on carbon capture and storage (CCS) to achieve that objective, suggesting in some scenarios that without it costs would increase by between $30 \%$ and $300 \%$. However, experience with CCS (geological sequestration) remains limited (Global CCS Institute, 2018; MIT, 2018). This paper discusses the economic viability of CCS based on a cost-benefit analysis (CBA). CBA is the tool most often used by economists to evaluate policy interventions and in the public evaluation of technologies. The paper is therefore divided into two major components: the evaluation of the benefits of CCS and the costs, with a discussion around the different assumptions and scenarios that impact these values based on a review of the existing economic and technological literature. Although CBA is already applied in other industries such as chemicals, this paper focuses on the costs and benefits of CCS as applied to power generation from fossil fuels since "The burning of coal, natural gas, and oil for electricity and heat is the largest single source of global greenhouse gas emissions" (Environmental Protection Agency, 2018).

The benefits of CCS are represented by the social cost of carbon (SCC), which is a metric used to value each tonne of $\mathrm{CO}_{2}$ emissions avoided. Conceptually, it is the marginal environmental damage done by the marginal unit of $\mathrm{CO}_{2}$ emitted. The SCC represents the 'benchmark' against which proposed methods of carbon emissions reduction or sequestration are compared. If a technology provides for the avoidance of a tonne of $\mathrm{CO}_{2}$ at a cost less than the $\mathrm{SCC}$, then it is deemed to pass a cost-benefit test.

The cost estimates for CCS technologies that were carefully selected from the literature currently fail such a cost-benefit test. Additional economies of scale, of network, and of capacity planning are explored. We find that they are not large enough to tilt the balance in favour of CCS in light of the central SCC values that advise policy in the USA and Canada, the countries with the most CCS projects in operation, under construction or at an advanced state of planning (Global CCS Institute, 2018; MIT, 2018). However, although the individual technologies that together form CCS are mature, the latest estimates point to expected future decreases 'possibly $20 \%$ to $30 \%$ ' in their costs (Irlam, 2017). We also have to point out that CCS does not always fail the costbenefit test by a wide margin and changes in the assumptions incorporated in the SCC calculation methodology may shift the conclusion in favour of CCS. Moreover, the methodology itself has its own controversies.

An unambiguous point is that CCS remains unproven on a large scale within our context. The vast majority of operating CCS projects apply to other industries than power generation and only in 2014 the very first CCS-equipped power plant started operating in Canada (Larkin et al., 2018a); several more years of experience are needed to decrease costs and the uncertainties surrounding the costs. Moreover, the attractiveness of CCS also depends on the evolution of other competing technologies, like some renewables, which are not as mature as the technologies used in CCS and show the potential for larger cost decreases.

Based on the current knowledge, the economic and technological literature points to a potential niche role for CCS - applied in particular settings where the economics are favourable - but there is little evidence to suppose it is likely to play a central role in the shift to a lower carbon economy over the next two decades. The IEA continues to see a $12 \%$ contribution for CCS to emissions reductions in the power, industry and fuel 
transformation sectors (IEA, 2016), down from 19\% in 2009 (IEA, 2009), although the reasons for the adjustment are not pursued here. We have to emphasise though that a large enough increase in the SCC values that advise policy, which may come as the result of a change in the calculation methodology or an update in its assumptions, may correspondingly increase the role of CCS in reducing global carbon emissions, as long as the power generation projects anticipated to start operating over the next few years prove themselves to be economically and technologically viable.

The paper proceeds as follows: in Section 2, we rely on the study by Greenstone et al. (2011) to introduce the main integrated assessment models (IAMs) employed in deriving SCC values (Section 2.1), the main assumptions made in the process with a discussion of alternative assumptions (Section 2.2) and the resulting SCC values based on the chosen set of assumptions with a discussion of how alternative assumptions change these values (Section 2.3); in Section 3 we present cost estimates from the literature for the main components of the CCS process - capture (Section 3.1), transport (Section 3.2) and storage (Section 3.3) - and explore potential cost reductions, followed by the current state of CCS projects (Section 3.4) and policies for the successful deployment of CCS (Section 3.5); Section 4 concludes.

\section{Social cost of carbon}

\subsection{Integrated assessment models}

IAMs integrate knowledge from economics and science into a unified framework. Within this framework analysts obtain SCC estimates by making assumptions about four main steps. These are:

1 estimates of future emissions of greenhouse gases

2 effects of past and future emissions on our climate

3 effects of changes in our climate on the physical and biological environment

4 translation of environmental impacts into economic damages (Greenstone et al., 2011).

The three main IAMs used in the literature are:

1 FUND (climate framework for uncertainty, negotiation and distribution) developed by Richard Tol (Tol, 1999)

2 DICE (dynamic integrated climate and economy) developed by William Nordhaus [Nordhaus and Boyer (2000) and Nordhaus (2008) cited by Greenstone et al. (2011)]

3 PAGE (policy analysis of the greenhouse effect) developed by Chris Hope [Hope (2006, 2008) cited by Greenstone et al. (2011)].

Although modelling differences between these IAMs exist, at the core of it all three translate emissions into loss functions. Greenstone et al. (2011) decided to give all three IAMs equal weight in their analysis.

One of the main criticisms of IAMs is that "there is no economic theory behind the loss function; it is simply made up. Nor are there data on which to base the parameters of 
the function; instead the parameters are simply chosen to yield moderate losses that seem 'reasonable' (e.g., $1 \%$ or $2 \%$ of GDP) from moderate temperature increases (e.g., $2^{\circ} \mathrm{C}$ or $\left.3^{\circ} \mathrm{C}\right)$ " [Pindyck, (2013), p.44]. Moreover, "factors of production, namely labour and capital and their total factor productivity (TFP) are not directly impacted, meaning that climate change has no effect, or only a very weak effect, on GDP growth" [Moore and Diaz, (2015), p.127]; this is assumed globally, despite the fact that the historical study by Dell et al. (2012) on temperature fluctuations and their impact on aggregate economic outcomes from 1950 to 2003 shows large, negative effects on growth in poor countries of about $-1.3 \%$ for a $1{ }^{\circ} \mathrm{C}$ rise in a given year.

\subsection{Main assumptions}

The main assumptions necessary to derive a SCC with the help of IAMs pertain to

1 socio-economic and emissions trajectories

2 equilibrium climate sensitivity (ECS)

3 discount rate

4 global or domestic SCC

5 equity weighting.

Five socio-economic and emissions trajectories were selected by Greenstone et al. (2011) from EMF-22, the Stanford Energy Modelling Forum exercise (Clarke and Weyant, 2009), because they have the advantage of internally consistent GDP, population and emission trajectories. Four of the selected trajectories represent business-as-usual (BAU) scenarios associated with $\mathrm{CO}_{2}$ concentrations between 612 and 889 parts per million $(\mathrm{ppm})$ in 2100 . The fifth achieves stabilisation at $550 \mathrm{ppm}$.

ECS is the resulting long-term increase in average global surface temperature from doubling atmospheric $\mathrm{CO}_{2}$ concentration relative to pre-industrial levels. It is, unsurprisingly, very unpredictable. Using the framework of feedback analysis, Roe and Baker (2007) showed that uncertainties in climate processes and hence feedbacks, are highly amplified in the resulting climate sensitivities. It follows that reducing uncertainties in the individual processes will have little effect in reducing uncertainty about the climate sensitivity. Recognising the inherent uncertainty of the ECS parameter, Greenstone et al. (2011) selected four candidate distributions: Roe and Baker (2007), log-normal, gamma and Weibull.

The discount rate may be the most controversial parameter in an IAM. It represents the marginal rate of substitution between consumption in different time periods. The SCC is essentially the damage in terms of reduced consumption due to higher temperature which results from one more tonne of carbon emitted. Since $\mathrm{CO}_{2}$ has a half-life of around 100 years, it means that one extra tonne of $\mathrm{CO}_{2}$ will produce a stream of damages that spans over decades. Each of these damages is discounted to the year when the extra tonne of $\mathrm{CO}_{2}$ was emitted and then they are all summed up. Therefore, the size of the discount rate has a significant impact on the SCC and on judging whether a CCS project is worth undertaking or not. The debate in the literature is not only about the appropriate size of the discount rate, but also about the appropriate method of discounting. After a thorough review of alternative methods, Greenstone et al. (2011) decided to largely follow Arrow's et al. (1996) descriptive approach. Arrow et al. (1996) outlined a descriptive and a 
prescriptive approach to discounting. The descriptive approach relies mostly on people's choices of saving and consumption levels and investment portfolio allocation decisions. Thus the discount rate is usually inferred from market rates of return. The prescriptive approach is based on a social welfare function that incorporates normative judgements on interpersonal comparisons of utility and weights assigned to the welfare of different generations.

A classic alternative approach to formulating the discount rate is given by the Ramsey (1928) equation: $r=\delta+\eta g$, where $\delta$ is the pure rate of time preference, $\eta$ is the elasticity of the marginal utility of consumption and $g$ is the growth rate of per capita consumption. Based on the existing economic literature, Greenstone et al. (2011) point out that the value of $\eta$ usually lies between 0.5 and 3, while the value of $\delta$ lies between 0 and 3 . Dasgupta (2008) argues for a value of $\eta$ higher than 1 and as high as 3 because $\eta=1$ is not consistent with the observed saving behaviour. Advocates of a zero pure rate of time preference like Arrow et al. (1996) and Stern et al. (2006) argue that anything higher than that would unjustly discriminate against future generations. Both parameters are equally important when this discount formulation is applied to a SCC analysis (Anthoff et al., 2009).

Weitzman (1998) argues that the discount rate used should not be constant, but should decline over time and therefore the far-distant future should be discounted at the lowest possible rate. This conclusion is supported by the use of an average of discount factors instead of a discount factor based on the average of discount rates when uncertain about the appropriate numerical value for the discount rate. Based on a survey of 2,160 $\mathrm{PhD}$ level economists and given that $\mathrm{CO}_{2}$ has a half-life of about 100 years, Weitzman (2001) concludes that the damage at that point in the future should be discounted by a rate around 13. Regarding the famous and controversial study by Stern et al. (2006), Weitzman (2007) concludes that "...the Stern Review predetermines the outcome in favor of strong immediate action to curtail greenhouse gas emissions by creating a very low value of $\mathrm{r} \approx 1.4 \%$ via the indirect route of picking point-estimate parameter values $\delta \approx 0$ and $\eta \approx 1$ that are more like theoretically reasoned extreme lower bounds than empirically plausible estimates of representative tastes. But we have also seen that a fair recognition of the truth that we are genuinely uncertain about what interest rate should be used to discount costs and benefits of climate changes a century from now brings discounting rates down from conventional values $r \approx 6 \%-7 \%$ to much lower values of perhaps $\mathrm{r} \approx 2 \%-4 \%$, which would create a more intermediate sense of urgency somewhere between what the Stern Review is advocating and the more modest measures to slow global warming advocated by many of its critics" [Weitzman, (2007), p.723]. Nordhaus (2007, p.701) confirms that "The Review's unambiguous conclusions about the need for extreme immediate action will not survive the substitution of assumptions that are more consistent with today's marketplace real interest rates and savings rates."

Due to the uncertainty of future interest rates and the on-going debate regarding the appropriate discounting method, Greenstone et al. (2011) decided to use three certainty-equivalent constant discount rates over a range considered plausible: $2.5 \%, 3 \%$ and $5 \%$.

A marginal tonne of $\mathrm{CO}_{2}$ emitted translates into damages that manifest globally, not just in the emitting country. Greenstone et al. (2011) decided to take total damages into account when pricing the SCC for two reasons: first, external damages are negative externalities that an emitting country imposes on a global level and second, climate change is a problem that one country cannot solve on its own. 
Recognising that the emission of $\mathrm{CO}_{2}$ produces global damages entails recognising that the well-being of people around the world is impacted differently: people with lower incomes are affected disproportionately by the same loss of income relative to people with higher incomes. Equity weighting would give people with lower incomes a higher weighting in the calculation of a SCC. Since the SCC values derived by Greenstone et al. (2011) were intended for US regulatory analysis, the authors decided not to take this approach.

\subsection{Social cost of carbon estimates}

The results from running the outlined IAMs by Greenstone et al. (2011) with the chosen set of assumptions consist of 45 ( 3 models $\times 3$ discount rates $\times 5$ socio-economic scenarios) separate distributions (due to ECS distributions) of SCC for each given year. Thus about 643 of estimates were lower than $\$ 20$ and about 863 were lower than $\$ 40$, meaning only about 143 of estimates were higher than $\$ 40$. Based on these values, Greenstone et al. (2011) recommended that the central value for SCC to be used in CBAs for potential federal regulations should be around $\$ 21$ and sensitivity analysis should be conducted at $\$ 5, \$ 35$ and $\$ 65$ levels in 2010, where the last value represents the 95th percentile of the SCC distribution at $3 \%$ discount rate to account for higher-than-expected impacts. As more $\mathrm{CO}_{2}$ is emitted, the climate changes more and this puts increasingly more stress on physical and economic systems. Thus the marginal tonne of emitted $\mathrm{CO}_{2}$ becomes increasingly damaging in time. According to the annualised rates of increase $3.1 \%, 1.9 \%, 1.6 \%$ corresponding to the SCC values at the $5 \%, 3 \%$ and $2.5 \%$ discount levels, respectively, for 2015 the recommended central value would be around $\$ 24$ and sensitivity analysis should be conducted at \$6, \$38 and \$73 (2007\$).

Introducing equity weightings in the process of estimating the SCC would normally alter the estimates significantly. Anthoff et al. (2009) explored these implications within the framework of FUND. The selected pure rates of time preference were $0 \%, 1 \%$ and $3 \%$. The socio-economic and emissions trajectories were based on four IPCC (Nakicenovic and Swart, 2000) scenarios and the default FUND scenario (Tol, 1999). When the SCC is positive, introducing weightings can even make a difference of $1^{\circ}$ of magnitude in the cost associated with one marginal tonne of $\mathrm{CO}_{2}$. In the case of a $0 \%$ discount rate, in three of the five scenarios the SCC estimates are around or below $\$ 100$, but once equity weighting is included they increase to over $\$ 1,000$.

Incorporating the impact of higher temperatures on TFP as mentioned in the IAMs section also alters the SCC estimates significantly. Moore and Diaz (2015) account for this effect within a DICE framework and arrive at an SCC estimate of \$220 (2005\$).

Tol (2008) provides a very useful meta-analysis of papers that attempted to estimate the SCC; it is an update on a similar project published earlier by Tol (2005). The meta-analysis comprises 211 estimates, mostly in 1995\$ and discounted to 1995; the author follows suit. Several useful results emerge. Estimates from the peer-reviewed literature are significantly lower and less uncertain than those from the gray literature. The kernel distribution shifts to the left for more recent studies, implying decreasing estimates of SCC; however, the author did not find the differences to be statistically significant when he looked at means and standard deviations. The controversial SCC estimate by Stern et al. (2006) lies between 90th and 94th percentile depending on the kernel density; lies beyond the 95th percentile when compared to the peer- reviewed literature, therefore it is an outlier. The median of the Fisher-Tippett kernel density 
including only peer-reviewed estimates, with a $3 \%$ pure rate of time preference and no equity weighting is $\$ 20 / \mathrm{tCO}_{2}$. This is within around $\$ 3$ from the similar estimate by Greenstone et al. (2011) when also discounted to 1995.

Confirming that an estimate of the SCC will never be entirely accurate, but continuous efforts to get closer to the true value should be made, the US government updated the 2010 value in 2013 and 2016 (Interagency Working Group on SCC, 2013; Interagency Working Group on Social Cost of Greenhouse Gases, 2016). This was the result of updates in IAMs and no other assumptions from Greenstone et al. (2011) were affected. Between 2010 and 2013, all estimates went up sharply, with the central value at the 3\% discount rate increasing from $\$ 21$ to $\$ 31$ and sensitivity analysis to be conducted at $\$ 10, \$ 50$ and $\$ 86$. The updated rates of yearly increase yield a central value for the SCC of around $\$ 36$ for 2015 , with sensitivity analysis to be conducted at $\$ 11, \$ 56$ and $\$ 105$ (2007\$). In the latest update the Interagency Working Group on Social Cost of Greenhouse Gases (2016) report suggested a 2020 central estimate of $\$ 42$ (2007\$), with sensitivity conducted at $\$ 12, \$ 62$ and $\$ 123$.

The Greenstone et al. (2011) estimate of the SCC is arguably one of the most known, but other countries have issued their own estimates to inform their own policy recommendations. For example, Environment Canada (2013) used a value of $\sim \mathrm{C} \$ 31 / \mathrm{tCO}_{2}$ for 2012 with sensitivity analysis conducted at $\mathrm{C} \$ 124 / \mathrm{tCO}_{2}$ reflecting arguments of Weitzman (2011) (2011C\$). The central SCC value was updated to $\$ 41 / \mathrm{tCO}_{2}$ in 2016 (discounted at 3\%, C\$ 2012, an increase of 30\%) and an upper value of $\$ 167 / \mathrm{CO}_{2}$ for sensitivity analysis (Environment and Climate Change Canada, 2016). In the UK, Clarkson and Deyes (2002) arrived at a central recommendation of $£ 70 / \mathrm{tC}$ which incorporates equity weighting, within a range of $£ 35 / \mathrm{tC}$ to $£ 140 / \mathrm{tC}$, all estimates rising at $£ 1 / \mathrm{tC}$ per year from 2000 on $(2000 £)$.

To sum up, the estimates of SCC are highly dependent on the IAMs and the set of assumptions adopted for their calculation. Among the assumptions, the discount rate and the inclusion of equity weightings appear to have the most significant impact on final estimates. Also accounting for impacts on TFP can raise SCC estimates significantly.

\section{Carbon capture and storage}

\subsection{Capture}

Several $\mathrm{CO}_{2}$ capture technologies exist, each of them best suited to specific power generation technologies. The ones included in the analysis by Global Carbon Capture and Storage Institute (Global CCS Institute, 2009, 2011; Irlam, 2017) have been proven in various pilot or demonstration projects involving post-combustion capture [supercritical pulverised coal (PC) boiler, ultra-supercritical PC boiler, natural gas-fired combined cycle (NGCC)]; pre-combustion capture using integrated gasification combined cycle (IGCC); oxy-combustion.

The capital expense is the most significant cost for a CCS-equipped power plant. In order to assess potential cost savings as technologies evolve from first-of-a-kind (FOAK) to nth-of-a-kind (NOAK) projects, two cost measures are used in the CCS literature: cost of $\mathrm{CO}_{2}$ captured and cost of $\mathrm{CO}_{2}$ avoided. The cost of $\mathrm{CO}_{2}$ captured estimates are lower than the cost of $\mathrm{CO}_{2}$ avoided estimates because the process of capture itself uses up energy that emits additional $\mathrm{CO}_{2}$. For the Shell Quest project in Canada, for example, the 
anticipated capture rate was $35 \%$ with the net $\mathrm{CO}_{2}$ reduction of $17 \%$ after the energy penalty (Larkin, 2017). Thus the more relevant cost for our analysis is the cost of $\mathrm{CO}_{2}$ avoided.

The most recent GCCSI estimates for cost of $\mathrm{CO}_{2}$ avoided are provided by Irlam (2017) and include allowances for storage and transport costs. The FOAK estimates for the above mentioned capture technologies vary between $\$ 58$ and $\$ 85$, whereas the NOAK estimates vary between $\$ 38$ and $\$ 48$ per tonne of $\mathrm{CO}_{2}$ avoided (2007\$). While the FOAK estimates are well above the USA 2020 central estimate for the SCC of $\$ 42$, the NOAK interval of estimates includes the SCC central estimate, and it is well below the upper recommended values for sensitivity analysis of $\$ 62$ and $\$ 123$ (Interagency Working Group on Social Cost of Greenhouse Gases, 2016). The NOAK interval remains higher than \$31 (2007\$), which is the equivalent of the C\$45 (2012C\$) 2020 central estimate used in Canada, but it is likewise well below the upper recommended values for sensitivity analysis (Environment and Climate Change Canada, 2016).

Another relevant figure for our analysis is the $\mathrm{CO}_{2}$ credit value breakpoint, the SCC figure above which it is economically feasible to build a CCS-equipped plant, rather than a regular plant. Below the credit value breakpoint, it is more beneficial to build a regular plant and pay for emissions in the form of a tax equal to the SCC. In the Global CCS Institute (2011) analysis, oxyfuel has the lowest breakpoint at around $\$ 52 / \mathrm{t} \mathrm{CO}_{2}$, for supercritical technologies the breakpoint is around $\$ 76 / \mathrm{tCO}_{2}$, while NGCC has the highest breakpoint at approximately $\$ 107 / \mathrm{t} \mathrm{CO}_{2}$ due to lower emission intensity of natural gas and higher cycle efficiency $(2007 \$)$. Although there is variation among technologies, these estimates are higher than the central SCC values used for policy analysis in the USA and Canada and they can be higher or lower than the above mentioned SCC values selected for sensitivity analysis.

Taken together these sets of estimates do not provide a clear picture on the viability of CCS, however the NOAK estimates for cost of $\mathrm{CO}_{2}$ avoided indicate that some CCS technologies may play an important role in the energy strategy of some countries as they transition toward low carbon economies. We also have to mention that these cost estimates are generated assuming that the project is financed through $40 \%$ debt at an interest rate of $6 \%$ and $60 \%$ equity with a rate of return of $12 \%$, which can be more costly than if the project was financed through public funds.

\subsection{Transport}

The transport component of the CCS process is very well known. Transport of $\mathrm{CO}_{2}$ by pipeline, ships, trains or trucks is applied daily around the world. Given the scale of transport infrastructure that will have to be deployed for large-scale CCS, transport by pipeline or ship are arguably the most viable options. Transport by ship is most likely to occur in regions of the world where there is limited access to onshore storage reservoirs, which is unlikely to be the case of the USA and Canada. A good overview of maritime transportation is provided by Decarre et al. (2010). Since even for offshore storage pipelines are needed to connect the source with the port and onshore storage is likely to be two to three times cheaper than offshore storage, most literature focuses on transport by pipeline and we follow suit in this study.

In the 2011 economic assessment update by the GCCSI, the reference case consists of one source, one storage site and $100 \mathrm{~km}$ of direct pipeline between the two. The length was chosen to reflect the average length of pipeline that was in use in large-scale 
integrated CCS projects. The average pipeline for onshore projects operating or in an advanced stage of development (sequestration and EOR) is currently approximately $150 \mathrm{~km}$ (calculation based on Global CCS Institute, 2018). The actual cost is thus potentially underestimated. The main insight to be gained is that there are benefits from cooperation between sources. In the reference case the source captures $4 \mathrm{Mt} \mathrm{CO}_{2} / \mathrm{yr}$ which results in a pipeline diameter of about $0.5 \mathrm{~m}$. Doubling the diameter of the pipeline to $1 \mathrm{~m}$, which is feasible, results in a quadrupling of the maximum $\mathrm{CO}_{2}$ flow, so now four similar sources can use the same pipeline. Therefore, based on the Global CCS Institute (2011) estimates, economies of scale may reduce transportation costs from around $\$ 1.43 / \mathrm{tCO}_{2}$ to around $\$ 0.57 / \mathrm{tCO}_{2}(2007 \$)$.

Future CCS projects are likely to consist of multiple sources and/or sinks connected by a network of pipelines. To facilitate decision making in such a complex environment, Middleton and Bielicki (2009, p.1052) introduce a geospatial-optimisation, economic-engineering model, called SimCCS (scalable infrastructure model for carbon capture and storage): "A comprehensive CCS infrastructure model should simultaneously con- sider and integrate seven key decisions: (1) how much $\mathrm{CO} 2$ to capture (2) at which sources; (3) where to construct pipelines and (4) of what size; (5) which reservoirs should store $\mathrm{CO} 2$ and (6) how much to inject; and (7) how to distribute $\mathrm{CO} 2$ from the dispersed sources through the network to the reservoirs."

Presenting and analysing the mathematics of the model is beyond the scope of this study. At the core of it, the model is similar to many classic economic problems: minimising total cost, which includes fixed infrastructure costs and operating costs, given a target $\mathrm{CO}_{2}$ capture/storage amount and a series of other technological and economic constraints.

Kuby et al. (2011) illustrate the benefits of networking by using SimCCS in a Midwest USA case study. The purpose of the exercise is to compare a project that takes advantage of SimCCS to network pipelines with a project in which only direct source-sink pipelines are used. For systems with more than one source and one sink, the length of the pipelines is on average $43 \%$ lower for the networked system than for the direct system while achieving on average $12 \%$ higher capacity utilisation. These results in $2 \%$ lower capture costs, $34 \%$ lower transport costs, $22 \%$ lower sink costs for total average savings of $6.5 \%$ in the networked system relative to the direct system.

So far we have seen economies that can be achieved in a static environment. Middleton et al. (2012b) investigate economies of capacity planning in a dynamic environment with the help of a different model: SimCCST IME. Succinctly put, it is SimCCS with variables indexed for time, resulting in an objective function that minimises fixed and variable costs over multiple time periods. The model is demonstrated using a hypothetical CCS project in Texas. Like SimCCS, SimCCSTIME takes advantage of networking to achieve economies of scale and utilisation. A significant difference is the existence of vastly underutilised pipelines in the first periods which are built with higher capacity than initially necessary in order to take advantage of large economies of scale in the later periods. For comparison reasons a greedy-add scenario is created. In this scenario pipeline capacity is added as needed from period to period, ignoring future requirements for $\mathrm{CO}_{2}$ capture and taking into account already existing infrastructure. Naturally, the greedy-add network ends up being longer than the SimCCST IME network since it creates capacity as needed and ends up running parallel pipelines on some segments. In the scenario analysed, it is twice as long $(1,167 \mathrm{~km}$ vs. $638 \mathrm{~km})$ and it costs over $50 \%$ more $\left(\$ 1.97 / \mathrm{tCO}_{2}\right.$ vs. $\$ 1.29 / \mathrm{tCO}_{2}$ in $\left.2007 \$\right)$. 
It should be noted that the above savings can only be fully realised if there is costless cooperation among sources. Morbee (2014) highlights the benefits of international cooperation using the pipeline network optimisation model InfraCCS. It is based on SimCCS by Middleton and Bielicki (2009); it adds techniques from computational geometry and a time component (Morbee et al., 2011). InfraCCS is used to derive the optimal pipeline network in Europe with and without international cooperation.

Under a joint international optimisation regime, the cost of the entire network is $€ 28$ billion, while the total cost of the non-cooperative case reaches $€ 82.1$ billion. Therefore, benefits from cooperation are significant at $€ 54.1$ billion. The allocation of these benefits will depend on each country's bargaining power. Bargaining power is derived from storage rent, for countries with excess $\mathrm{CO}_{2}$ storage over the quantity of $\mathrm{CO}_{2}$ captured in the country and from transit rent, for countries whose locations allow for shortcuts between sources and sinks. Two cases are considered: one with national $\mathrm{CO}_{2}$ pipeline monopolies and one with liberalised $\mathrm{CO}_{2}$ pipeline construction. Based on the two cases, countries with excess storage capacity capture $38 \%-45 \%$ of the benefits from cooperation, with the higher percentage corresponding to the liberalised case. The equivalent rent is $€ 5-6 / \mathrm{tCO}_{2}$, increasing the cost of storage by $25 \%-600 \%$. Countries with strategic locations capture $19 \%$ of the benefits in the case of national pipeline monopolies, but this rent can be eliminated through liberalisation.

These studies point out that while benefits from cooperation are significant for CCS pipeline networks, they are not necessarily going to be fully realised and the benefits are going to be unevenly split among participants. Incorporating these considerations may affect the scale of some CCS projects or even their viability altogether. Indeed, with the exception of the Weyburn EOR project, no cross-border pipelines/CCS projects are operating or in an advanced stage of development (Global CCS Institute, 2018).

\subsection{Storage}

A good overview of the geological storage component in the CCS process is provided by Bachu (2008) and Bui et al. (2018); three ways of sequestering carbon-geological (saline aquifer) storage, ocean storage and surface mineral carbonation have been considered to date.

Surface mineral carbonation is automatically excluded from consideration for the short to medium-term due to high cost, environmental impact and high energy requirements. Ocean storage is an option still pursued scientifically and experimentally, but not seriously considered for large-scale implementation in the short-term due to poorly understood cost, environmental impact, storage efficiency, physical and chemical processes. Saline aquifer geological sequestration is better understood as demonstrated by experience in oil and gas industries, appears to have a relatively low cost and seems to have the necessary capacity to store the required quantities of $\mathrm{CO}_{2}$. It is thus the more feasible of the three options, the one of the three that is most actively pursued and studied, with large scale integrated projects in operation and advanced stage of development and the only one we take into consideration in this study.

Saline aquifers hold injection characteristics necessary to store large volumes of $\mathrm{CO}_{2}$ over their economic lives of around 40 years and are believed to be reliable for long-term storage (Larkin et al., 2018b, 2018c). To identify one suitable site, five or more sites may have to be characterised. Even if storage cost likely represents a small portion for a CCS project, the cost of finding a suitable site can increase storage cost from around $\$ 5 / \mathrm{tCO}_{2}$ 
for best case scenario to about $\$ 8-9 / \mathrm{tCO}_{2}$ for worst case scenario, a $60 \%-80 \%$ increase. A total finding cost of $\$ 150$ million is considered to be the economic threshold beyond which investigations would be abandoned. Even once a suitable site is identified, its characteristics may not be ideal. A reservoir with low permeability thickness product will have a limited injection rate (Bachu, 2015). In order to store all the $\mathrm{CO}_{2}$, additional wells are needed, which increases costs. While a poor reservoir could double the storage cost from $\$ 6 / \mathrm{tCO}_{2}$ to $\$ 12 / \mathrm{tCO}_{2}$ (Global CCS Institute, 2011) (2007\$), Vikara et al. (2017) indicated the potential in the USA to store $500-2,000 \mathrm{Gt}$ at or below $\$ 10 / \mathrm{tCO}_{2}$ and 2000-4000 Gt under $\$ 25 / \mathrm{tCO}_{2}$. Moreover, NETL (2017) provides an online saline sequestration (storage) cost model.

Nevertheless, uncertainty of storage site characteristics may persist after a site was deemed suitable enough for geological sequestration due to technological limitation and/or financial constraints. Middleton et al.(2012a) show how that uncertainty shapes the transport and storage infrastructure. It is based on an earlier paper by Keating et al. (2011). One eloquent example given by the authors is that: "A large utility making decisions about how much $\mathrm{CO}_{2}$ to capture from a selection of power plants might preferentially choose a smaller and more costly storage reservoir with low uncertainty rather than a larger, cheaper alternative that exposes them to the risk of not being able to store all the $\mathrm{CO}_{2}$ they produce" [Middleton et al., (2012a), p.132]. Middleton and Yaw (2018) explore and quantify transport and storage infrastructure decisions for a case study on oil sands emissions, Alberta, Canada. Best, average and worst case scenarios are discussed as the cost of getting it wrong, including stranded $\mathrm{CO}_{2}$.

\subsection{Demonstrating carbon capture and storage}

According to Global CCS Institute (2018) and MIT (2018), there are 27 integrated CCS projects active or in an advanced planning state. Eighty five percent of these have been driven by mature $\mathrm{CO}_{2}$ markets for $\mathrm{CO}_{2}$-enhanced oil recovery (EOR). However, few of these $\mathrm{CO}_{2}$-EOR projects engage in sufficient monitoring, measurement and verification to assess whether $\mathrm{CO}_{2}$ storage is likely to be permanent. In addition, $\mathrm{CO}_{2}$ is an expense to be minimised in these projects, whereas large-scale CCS (sequestration) projects would seek to safely maximise stored $\mathrm{CO}_{2}$. CCS-EOR projects have had limited usefulness, the notable exception being the Weyburn $\mathrm{CO}_{2}$-EOR project in Canada which monitored and verified the storage of approximately $2 \mathrm{Mt} \mathrm{CO}_{2} /$ year from a coal gasification project located in the USA (Larkin et al., 2018a). Alberta's Shell Quest CCS (saline sequestration) project came on stream in 2015 and is on track to store the planned 1 $\mathrm{MtCO}_{2} / \mathrm{yr}$ (Global CCS Institute, 2018).

Nykvist (2013) identified four main challenges that are greater than presently thought in moving beyond the current demonstration stage:

- tenfold scaling-up in size from pilot plants to commercial demonstration projects

- tenfold increase in the number of constructed large-scale demonstration plants

- tenfold increase in annual funding needed for the next 40 years

- tenfold increase in the price of $\mathrm{CO}_{2}$ emissions.

Herzog (2011) also pointed to the integration and scaling up of CCS components as the main challenge to commercial deployment of the technology while Leiss and Krewski 
(2018) identify three broad categories of issues: "Government and industry factors (competent regulatory oversight; adequate risk assessment and risk management frameworks; and supportive public policy architecture); (2) Environmental risk factors (adequate site-specific characterisations of geological formations for CCS storage sites worldwide; credible monitoring of storage site performance; and the possibility of leaking from storage); and (3) Socio-economic factors (tolerable economic costs; public perceptions of risks and benefits; information provision, effective communication and stakeholder engagement; and social and public acceptability, including the use of decision support mechanisms)."

\subsection{Deploying carbon capture and storage}

What can be expected from demonstration projects is analysed by Scott (2013) for Europe. Eleven CCS proposals were still nominally active in 2011, but due to funding and other constraints, only about a third was expected to become reality. In fact, only one project in the UK remains under (early) development (Global CCS Institute, 2018). Based on three simple deployment scenarios (none, limited and considerable), she concludes that even if demonstration projects are successful, CCS may not deliver as expected. Strong political support is needed for a large scale deployment, such as strategic storage validation and pipeline planning and a clear process to make commercial CCS attractive to potential investors. Alphen et al. (2009) and Leiss and Krewski (2018) also point to the need of direct policy initiatives to encourage entrepreneurial activity and market formation for a continued strong innovation system.

Policies can play a major role in deciding whether CCS is deployed or not and on what scale. Using a top-down energy-economy model, Gerlagh and van der Zwaan (2006) show that only the carbon tax and portfolio standard for carbon intensity policies would make use of CCS for carbon mitigation [see also Larkin et al. (2018d), regarding the Canadian context]. In terms of instrument performance for climate stabilisation Gerlagh and van der Zwaan (2006) conclude that subsidising non-carbon energy is always the most expensive option. Taxing carbon and using the revenues for non-carbon energy resource is the most cost-efficient policy instrument to reach a stabilisation target. Ellerman et al. [(2000), cited by Otto and Reilly (2008)] found that the development of scrubbers to abate sulphur dioxide emissions was largely spurred through a technology standard. Yet the introduction of a sulphur dioxide cap-and-trade program in the USA, which was considered a more cost-effective policy, indeed led to a significant reduction in emissions, but with lower-scale deployment of scrubbers than under the technology standard. Therefore, while an environmental policy can lead to the development of a new technology, a cost-effective policy may not necessarily lead to its large-scale adoption (Otto and Reilly, 2008). Using a dynamic computable general equilibrium model that explicitly captures links between energy use, $\mathrm{CO}_{2}$ emissions, directed technical change and the economy, Otto and Reilly (2008) show that a combination of differentiated $\mathrm{CO}_{2}$ trading schemes and an adoption subsidy is the most effective in inducing CCS adoption; a combination of differentiated $\mathrm{CO}_{2}$ trading schemes and differentiated (between $\mathrm{CO}_{2}$-intensive and non- $\mathrm{CO}_{2}$-intensive economy sectors) $\mathrm{R} \& \mathrm{D}$ subsidies leads to fast enough adoption as well, while being cost-effective in achieving the abatement target. In a different model, but based on the same main idea, Loschel and Otto (2009, p.4) investigate the effects of technological uncertainty. CCS is the backstop technology whose arrival is anticipated or not. Their main policy recommendation is that: "policy 
makers should [. . .] be prudent in designing $\mathrm{CO}_{2}$ emission reduction policy and be careful not to let polluters become complacent by postponing some of their emission reduction efforts awaiting the silver bullet technology on the horizon."

CCS deployment will continue to meet barriers pertaining to the technology itself, government policies and competition from other technologies. Some of these barriers were identified by Davies et al. (2013) using an opinion survey completed by 229 CCS experts, including cost and cost recovery, lack of financial incentive or a price signal, long-term liability risks and lack of comprehensive regulatory frame (see also Larkin et al., 2018d, 2018e; Leiss and Krewski, 2018).

Leakage from reservoirs was ranked the number one risk of CCS by individuals working at stakeholder companies that shape CCS policy, including oil and gas companies, electric utilities, $\mathrm{CO}_{2}$-intensive industries and NGOs in a survey conducted by Johnsson et al. (2010). They all believed that CCS and renewables would play a major role in electricity generation over the following 10-20 years. However, how big a role CCS will play also depends on other technologies and their own risks, continued innovation, demonstration and cost reduction. For example, John Rogers of the University of Illinois has devised solar cells that may double the efficiency of solar panels and the new technology has the potential to become widely adopted (The Economist, 2014). Such significant progress in alternative power generation technologies showcases the cost reduction potential in renewables; it has a negative effect on the scale at which CCS is deployed and, as a consequence, on the incentives to invest in CCS. The Australian Energy Technology Assessment (AETA) from the Australian Government Bureau of Resources and Energy Economics provides periodic updates on projected cost curves. The AETA (2013) estimates show that the levelised cost of electricity (LCOE) for CCS technologies is indeed expected to decrease from 2025 to 2050, however the LCOE estimates for some renewables such as solar photovoltaic and onshore wind decrease more significantly and they become some of the cheapest options on the market. They are expected to compete with fossil fuels without CCS even at a zero carbon price. This is something that CCS can never achieve since it is based on and adds to the costs of fossil fuels technologies.

\section{Conclusions}

In this economic perspective on carbon capture and storage (saline aquifer sequestration), particularly in application to power generation, we focused on the two sides that constitute a CBA of this set of technologies: the SCC, which is the benefit to society of abating one tonne of carbon through CCS and the monetary cost of abating that tonne of carbon through CCS.

On the benefit side, the SCC estimates are highly sensitive to assumptions made during the estimation process. Based on their methodology and chosen set of assumptions, Greenstone et al. (2011) estimated a SCC central value of \$24 for 2015. Due to improvements in the science of the IAMs, this figure was updated by the Interagency Working Group on SCC in 2013 to $\$ 36$, with sensitivity analysis to be conducted at $\$ 11, \$ 56$ and $\$ 105$ (2007\$). In the latest update the Interagency Working Group on Social Cost of Greenhouse Gases (2016) report suggested a 2020 central estimate of $\$ 42(2007 \$)$, with sensitivity conducted at $\$ 12, \$ 62$ and $\$ 123$. Lowering the discount rate to $0 \%$ and introducing equity weightings can result in some SCC estimates 
in excess of $\$ 1,000$ (Tol, 2008). Accounting for temperature impacts on TFP can result in SCC estimates of over $\$ 200$ (Moore and Diaz, 2015). However, the more relevant figures remain the ones adopted by policy makers for CBAs.

There are numerous measures for the cost of CCS in the literature and different studies may highlight different measures, depending on the purpose of the study. The more relevant ones for our analysis are the cost of avoiding $\mathrm{CO}_{2}$ and the $\mathrm{CO}_{2}$ credit value breakpoint. Depending on the CCS technology, in theoretical reference scenarios, the latest estimates for the former vary between approximately $\$ 38 / \mathrm{tCO}_{2}$ and $\$ 48 / \mathrm{tCO}_{2}$ for nth-of-a-kind plants (Irlam, 2017), and the latter between approximately $\$ 52 / \mathrm{tCO}_{2}$ and $\$ 107 / \mathrm{tCO}_{2}$ (Global CCS Institute, 2011) (2007\$). The cost of $\mathrm{CO}_{2}$ avoided estimates include transport and storage costs in the range of $\$ 6$ to $\$ 11 / \mathrm{tCO}_{2}$. There are limited opportunities to decrease capital costs, but we have to keep in mind that the above cost estimates should be lower in the case of projects financed through public funds due to lower financing costs. Opportunities to decrease capture and storage costs exist through networking and cooperation among sources and sinks (Kuby et al., 2011; Middleton et al., 2012b). However, they represent a small portion of the costs and the realised proportion of savings is subject to transit and storage rent extraction (Morbee, 2014).

Based on the above figures, the lower bounds for the total cost of avoiding $\mathrm{CO}_{2}$ through $\mathrm{CCS}$ and the $\mathrm{CO}_{2}$ credit value breakpoint are $\$ 38$ and $\$ 52$, respectively. The former is currently lower than the 2020 central SCC estimate of $\$ 42$, but still higher than the central estimate of $\$ 31$ in Canada (2007\$). The latter is higher than the central SCC values both in the USA and Canada, however updated estimates may show lower figures in light of the more recent, lower estimates on the cost of avoiding $\mathrm{CO}_{2}$ (Global CCS Institute, 2011; Irlam, 2017). The first-of-a-kind plant estimates for cost of $\mathrm{CO}_{2}$ avoided range higher between $\$ 58$ and $\$ 85$, and only with gained experience over time the nth-of-a-kind lower bounds may be reached. They are nonetheless lower than the highest values of SCC used for sensitivity analysis both in the USA and Canada, and while most studies recognise that $\mathrm{CCS}$ technologies are indeed too expensive today, it is also true that the SCC will continue to escalate. In 10-15 years some CCS technologies are expected to be a viable option from a CBA perspective. Supporters of CCS often focus on this point when they argue that technology and environmental policies should ensure that CCS is ready for full deployment at that point; Gerlagh and van der Zwaan (2006), Otto and Reilly (2008) and IEA (2016) make good policy recommendations for successful CCS deployment. However, within the same time frame some renewable power generation technologies are expected to be cheaper than CCS technologies and by 2050 they are expected to be cheaper even than conventional coal and gas power generation technologies (AETA, 2013). CCS-equipped power plants have the advantage of being reliable and CCS technologies are currently the only technological abatement option in some industries where carbon emissions continue to be an unavoidable by-product (IEA, 2016, 2018).

Based on the current information we expect CCS to be deployed on a limited scale as a back-up for energy generation and as the only technological carbon mitigation option in some industries. There are several factors that may speed up CCS deployment and/or increase its role in carbon mitigation from a CBA perspective. On the benefit side of the $\mathrm{CBA}$, an increase in the SCC may arrive as a result of science updates in IAMs - such as the inclusion of impacts on TFP, as a result of changes in assumptions - especially a decrease in discount rates or the inclusion of equity weighting, or as a result of changing the methodology altogether. As more CCS projects applied to power generation are 
deployed, lower uncertainty surrounding costs, evidence of their economic viability and greater government involvement to reduce financing costs may lower the cost side of the CBA. Weaker than expected cost decreases for renewable technologies would also make the case for a greater CCS role.

\section{References}

AETA - Australian Government Bureau of Resources and Energy Economics (2013) Australian Energy Technology Assessment 2013 Model Update, Canberra, Australia [online] http://bree.slicedlabs.com.au/publications/australian-energy-technology-assessments (accessed 7 July 2013).

Alphen, K.v., Ruijven, J.v., Kasa, S., Hekkert, M. and Turkenburg, W. (2009) 'The performance of the Norwegian carbon dioxide, capture and storage innovation system', Energy Policy, Vol. 37, No. 1, pp.43-55.

Anthoff, D., Tol, R. and Yohe, G. (2009) 'Risk aversion, time preference, and the social cost of carbon', Environmental Research Letters, Vol. 4, No. 2, 1-7.

Arrow, K.J., Cline, W.R., Maler, K-G., Munasinghe, M., Squitieri, R. and Stiglitz, J.E. (1996) 'Intertem-poral equity, discounting and economic efficiency', in Bruce, J.P. et al. (Eds.): Climate Change 1995: Economic and Social Dimensions of Climate Change, Contribution of Working Group III to the Second Assessment Report of the Intergovernmental Panel on Climate Change, pp.125-144, Cambridge University Press, Cambridge, UK.

Bachu, S. (2008) ' $\mathrm{CO}_{2}$ storage in geological media: role, means, status and barriers to deployment', Progress in Energy and Combustion Science, Vol. 34, No. 2, pp.254-273.

Bachu, S. (2015) 'Review of $\mathrm{CO}_{2}$ storage efficiency in deep saline aquifers', Int. J. Greenhouse Gas Control, Vol. 40, pp.188-202, DOI: 10.1016/j.ijggc.2015.01.007.

Bui, M., Adjiman, C.S., Bardow, A., Anthony, E.J., Boston, A., Brown, S., Fennell, P.S., Fuss, S., Galindo, A., Hackett, L.A., Hallett, J.P., Herzog, H.J., Jackson, G., Kemper, J., Krevor, S., Maitland, G.C., Matuszewski, M., Metcalfe, I.S., Petit, C., Puxty, G., Reimer, J., Reiner, D.M., Rubin, E.S., Scott, S.A., Shah, N., Smit, B., Trusler, J.P.M., Webley, P., Wilcox, J. and Mac Dowell, N. (2018) 'Carbon capture and storage (CCS): the way forward', Energy and Environmental Science, Vol. 11, No. 5, pp.1062-1176, DOI: 10.1039/c7ee02342a.

Clarke, L. and Weyant, J. (2009) 'Introduction to the EMF 22 special issue on climate change control scenarios', Energy Economics, Vol. 31, Sup. 2, p.S6.

Clarkson, R. and Deyes, K (2002) 'Estimating the social cost of carbon emissions', Government Economic Service Working Paper 140, HM Treasury, London, UK.

Dasgupta, P. (2008) 'Discounting climate change', J. Risk and Uncertainty, Vol. 37, Nos. 2-3, pp.141-169.

Davies, L.L., Uchitel, K. and Ruple, J. (2013) 'Understanding barriers to commercial-scale carbon capture and sequestration in the United States: an empirical assessment', Energy Policy, Vol. 59, pp.745-761.

Decarre, S., Berthiaud, J., Butin, N. and Guillaume-Combecave, J-L. (2010) ' $\mathrm{CO}_{2}$ maritime transportation', International Journal of Greenhouse Gas Control, Vol. 4, No. 5, pp.857-864.

Dell, M., Jones, B.F. and Olken, B.A. (2012) 'Temperature shocks and economic growth: evidence from the last half century', American Economic Journal: Macroeconomics, Vol. 4, No. 3, pp.66-95.

Ellerman, A.D., Joskow, P.L., Schmalensee, R., Montero, J.P. and Bailey, E.M. (2000) Markets for Clean Air: The US Acid Rain Program, Cambridge University Press, Cambridge, UK.

Environment and Climate Change Canada (2016) Technical Update to Environment and Climate Change Canada's Social Cost of Greenhouse Gas Estimates [online] http://ec.gc.ca/cc/ default.asp?lang=En\&n=BE705779-1\#SCC-Sec2-2-3 (accessed 27 September 2018). 
Environment Canada (2013) 'Heavy-duty vehicle and engine greenhouse gas emission regulations', Canada Gazette, Vol. 147, No. 6 [online] http://laws-lois.justice.gc.ca/PDF/SOR-2013-24.pdf (accessed 9 October, 2018).

Environmental Protection Agency (2018) Global Greenhouse Gas Emissions Data [online] https://www.epa.gov/ghgemissions/global-greenhouse-gas-emissions-data (accessed 27 September 2018).

Gerlagh, R. and Zwaan, B.v.d. (2006) 'Options and instruments for a deep cut in $\mathrm{CO}_{2}$ emissions: carbon dioxide capture or renewable, taxes or subsidies?', The Energy Journal, Vol. 27, No. 3, pp. $25-48$.

Global CCS Institute (2009) Strategic Analysis of the Global Status of Carbon Capture and Storage, Report 2: Economic Assessment of Carbon Capture and Storage Technologies, Final Report, Canberra, Australia [online] http://www.canadiancleanpowercoalition.com/pdf/ GS29\%20-\%20Foundation-Report-2-rev-1.pdf (accessed 27 September 2018).

Global CCS Institute (2011) Economic Assessment of Carbon Capture and Storage Technologies: 2011 Update, Canberra, Australia [online] http://www.globalccsinstitute.com/publications/ economic-assessment-carbon-capture-and-storage-technologies-2011-update (accessed 7 July 2014).

Global CCS Institute (2018) Status of CCS Project Database [online] https://www.globalccsinstitute.com/projects/large-scale-ccs-projects (accessed 20 September 2018).

Greenstone, M., Kopits, E. and Wolverton, A. (2011) 'Estimating the social cost of carbon for use in U.S. federal rulemakings: a summary and interpretation', MIT Center for Energy and Environmental Policy Research Working Paper 2011-06, MIT, Cambridge, US [online] http://ceepr.mit.edu/files/papers/2011-006.pdf (accessed 9 October 2018).

Herzog, H.J. (2011) 'Scaling up carbon dioxide capture and storage: from megatons to gigatons', Energy Economics, Vol. 33, No. 4, pp.597-604.

Hope, C. (2006) 'The marginal impact of $\mathrm{CO}_{2}$ from PAGE 2002: an integrated assessment model incorporating the IPCC's five reasons for concern', The Integrated Assessment Journal, Vol. 6, No. 1, pp.19-56.

Hope, C. (2008) 'Optimal carbon emissions and the social cost of carbon under uncertainty', The Integrated Assessment Journal, Vol. 8, No. 1, pp.107-122.

IEA (2009) Technology Roadmap: carbon capture and storage [online] http://www.iea.org/ publications/freepublications/publication/technology-roadmap-carbon-capture-and-storage2009.html (accessed 10 May 2018).

IEA (2016) 20 Years of Carbon Capture and Storage [online] https://www.iea.org/publications/ freepublications/publication/20YearsofCarbonCaptureandStorage_WEB.pdf (accessed 20 August 2018).

IEA (2018) Industrial Applications of CCS [online] https://www.iea.org/topics/ccs/ industrialapplicationsofccs (accessed 8 September 2018).

Interagency Working Group on SCC (2013) Technical Support Document: Technical Update of the Social Cost of Carbon for Regulatory Impact Analysis Under Executive Order 12866 [online] http://environblog.jenner.com/files/technical-update-of-the-social-cost-of-carbon-forregulatory-impact-analysis-under-executive-order-12866.pdf (accessed 10 October 2018).

Interagency Working Group on Social Cost of Greenhouse Gases (2016) Technical Support Document: Technical Update of the Social Cost of Carbon for Regulatory Impact Analysis Under Executive Order 12866 [online] https://www.epa.gov/sites/production/files/ 2016-12/documents/sc_co2_tsd_august_2016.pdf. (accessed 27 September 2018).

Intergovernmental Panel on Climate Change (2014) Mitigation of Climate Change, Contribution of Working Group III to the Fifth Assessment, Cambridge University Press, UK and NY, USA.

Irlam, L. (2017) Global CCS Institute: Global Costs of Carbon Capture And Storage: 2017 Update [online] https://hub.globalccsinstitute.com/sites/default/les/publications/201688/global-ccscost-updatev4.pdf (accessed 22 June 2019). 
Johnsson, F., Reiner, D., Itaoka, K. and Herzog, H. (2010) 'Stakeholder attitudes on carbon capture and storage - an international comparison', International Journal of Greenhouse Gas Control, Vol. 4, No. 2, pp.410-418.

Keating, G.N., Middleton, R.S., Viswanathan, H.S., Stauffer, P.H. and Pawar, R.J. (2011) 'How storage uncertainty will drive CCS infrastructure', Energy Procedia, Vol. 4, pp.2393-2400.

Kuby, M.J., Middleton, R.S. and Bielicki, J.M. (2011) 'Analysis of cost savings from networking pipelines in CCS infrastructure systems', Energy Procedia, Vol. 4, pp.2808-2815.

Larkin, P. (2017) 'An integrated risk management framework for carbon capture and storage in the Canadian context', PhD Thesis [online] http://hdl.handle.net/10393/35881 (accessed 20 September 2018).

Larkin, P., Leiss, W. and Krewski, D. (2018a) 'The evolution of regulatory practice for CCS projects in Canada', Int. J. Risk Assessment and Management, in this issue.

Larkin, P., Dusseault, M., Gracie, R.G., Sarkarfarshi, A.M., Shafiei, A., Aspinall, W. and Krewski, D. (2018b) 'Risk management in carbon capture and storage: insights from a structured expert elicitation', Int. J. Risk Assessment and Management, in this issue.

Larkin, P., Dusseault, M., Gracie, R.G., Sarkarfarshi, A.M., Shafiei, A., Aspinall, W. and Krewski, D. (2018c) 'Uncertainty in risk issues for carbon capture and storage: findings from a structured expert elicitation', Int. J. Risk Assessment and Management, in this issue.

Larkin, P., Leiss, W., Arvai, J., Gracie, R.G., Fall, M., Dusseault, M.D., Heyes, A. and Krewski, D. (2018d) 'An integrated risk management framework for carbon capture and storage in the Canadian context', Int. J. Risk Assessment and Management, in this issue.

Larkin, P., Leiss, W. and Krewski, D. (2018e) 'Risk management frameworks for carbon capture and storage: a global perspective', Int. J. Risk Assessment and Management, in this issue.

Leiss, W. and Krewski, D. (2018) 'Environmental scan and issue awareness: risk management challenges for CCS', Int. J. Risk Assessment and Management, in this issue.

Loschel, A. and Otto V.M. (2009) 'Technological uncertainty and cost effectiveness of $\mathrm{CO}_{2}$ emission reduction’, Energy Economics, Vol. 31, Sup. 1, pp.S4-S17.

Massachusetts Institute of Technology (MIT) (2018) 'Carbon capture \& sequestration project database' [online] http://sequestration.mit.edu/tools/projects/index.html (accessed 19 August 2018).

Middleton, R.S. and Bielicki, J.M. (2009) 'A scalable infrastructure model for carbon capture and storage: SimCCS', Energy Policy, Vol. 37, No. 3, pp.1052-1060.

Middleton, R.S. and Yaw, S. (2018) 'The cost of getting CCS wrong: uncertainty, infrastructure design, and stranded $\mathrm{CO}_{2}$ ', International Journal of Greenhouse Gas Control, Vol. 70, No. Complete, pp.1-11, DOI: 10.1016/j.ijggc.2017.12.011.

Middleton, R.S., Keating, G.N., Viswanathan, H.S., Stauffer, P.H. and Pawar, R.J. (2012a) 'Effects of geologic reservoir uncertainty on $\mathrm{CO}_{2}$ transport and storage infrastructure', International Journal of Greenhouse Gas Control, Vol. 8, pp.132-142.

Middleton, R.S., Kuby, M.J., Wei, R., Keating, G.N. and Pawar, R.J. (2012b) 'A dynamic model for optimally phasing in $\mathrm{CO}_{2}$ capture and storage infrastructure', Environmental Modelling 8 Software, Vol. 37, pp.193-205.

Moore, F.C. and Diaz, D.B. (2015) 'Temperature impacts on economic growth warrant stringent mitigation policy', Nature Climate Change, Vol. 5, No. 2, pp.127-131.

Morbee, J. (2014) 'International transport of $\mathrm{CO}_{2}$ : who can gain and how much?', Environmental Resource Economics, Vol. 57, No. 3, pp.299-322.

Morbee, J., Serpa, J. and Tzimas, E. (2011) 'Optimal planning of $\mathrm{CO}_{2}$ transmission infrastructure: the JRC InfraCCS tool', Energy Procedia, Vol. 4, pp.2772-2777.

Nakicenovic, N. and Swart, R. (2000) Emissions Scenarios, Special Report of the Intergovernmental Panel on Climate Change, Cambridge University Press, Cambridge, UK. 
National Energy Technology Laboratory (2017) FE/NETL $\mathrm{CO}_{2}$ Saline Storage Cost Model, US Department of Energy [online] https://www.netl.doe.gov/research/energy-analysis/ search-publications/vuedetails?id=2403 (accessed 28 September 2018).

Nordhaus, W. (2007) 'A review of the "stern review on the economics of climate change', Journal of Economic Literature, Vol. 45, No. 3, pp.686-702.

Nordhaus, W. (2008) A Question of Balance: Weighing the Options on Global Warming Policies, Yale University Press, New Haven, CT.

Nordhaus, W. and Boyer, J. (2000) Warming the World: Economic Models of Global Warming, MIT Press, Cambridge, MA.

Nykvist, B. (2013) 'Ten times more difficult: quantifying the carbon capture and storage challenge', Energy Policy, Vol. 55, pp.683-689.

Otto, V.M. and Reilly, J. (2008) 'Directed technical change and the adoption of $\mathrm{CO}_{2}$ abatement technology: the case of $\mathrm{CO}_{2}$ capture and storage', Energy Economics, Vol. 30, No. 6, pp.2879-2898.

Pindyck, R.S. (2013) 'Pricing carbon when we don't know the right price', Regulation, Vol. 36, No. 2, pp.43-46.

Ramsey, F.P. (1928) ‘A mathematical theory of saving', The Economic Journal, Vol. 38, No. 152, pp.543-559.

Roe, G.H. and Baker, M.B. (2007) 'Why is climate sensitivity so unpredictable?', Science, Vol. 318, No. 5850, pp.629-632.

Scott, V. (2013) 'What can we expect from Europe's carbon capture and storage demonstrations?', Energy Policy, Vol. 54, pp.66-71.

Stern, N. et al. (2006) Stern Review: The Economics of Climate Change, HM Treasury, London, UK.

The Economist (2014) Solar Energy - Stacking the Deck [online] http://www.economist.com/news/ science-and-technology/21596924-way-double-efficiency-solar-cells-about-go-mainstreamstacking (accessed 7 July 7 2014).

Tol, R.S.J. (1999) 'The marginal cost of greenhouse emissions', The Energy Journal, Vol. 20, No. 1 , pp.61-81.

Tol, R.S.J. (2005) 'The marginal damage costs of carbon dioxide emissions: an assessment of the uncertainties', Energy Policy, Vol. 33, No. 16, pp.2064-2074.

Tol, R.S.J. (2008) 'The social cost of carbon: trends, outliers and catastrophes', Economics: The Open-Access, Open-Assessment E-Journal, Vol. 2, No. 25, pp.1-22 [online] http://hdl.handle.net/10419/18038 (accessed 9 October 2018).

United Nations Framework Convention on Climate Change (2015) Adoption of the Paris Agreement, FCCC/CP/2015/L.9 [online] http://unfccc.int/resource/docs/2015/cop21/eng/ 109.pdf (accessed 16 August 2018).

Vikara, D., Shih, C.Y., Lin, S., Guinan, A., Grant, T., Morgan, D. and Remson, D. (2017) 'U.S. DOE's economic approaches and resources for evaluating the cost of implementing carbon capture, utilization, and storage (CCUS)', Journal of Sustainable Energy Engineering, Vol. 5, No. 4, pp.307-340, DOI: 10.7569/jsee.2017.629523.

Weitzman, M.L. (1998) 'Why the far-distant future should be discounted at its lowest possible rate', Journal of Environmental Economics and Management, Vol. 36, No. 3, pp.201-208.

Weitzman, M.L. (2001) 'Gamma discounting', American Economic Review, Vol. 91, No. 1, pp.260-271.

Weitzman, M.L. (2007) 'A review of the "stern review on the economics of climate change", Journal of Economic Literature, Vol. 45, No. 3, pp.703-724.

Weitzman, M.L. (2011) 'Fat-tailed uncertainty in the economics of climate change', Review of Environmental Economic Policy, Vol. 5, No. 2, pp.275-292. 